\title{
IMPORTATION OF RELATIONAL PROJECT DELIVERY AGREEMENTS EXPLOITING THE BIM APPROACH IN LEGISLATION
}

\author{
GIUSEPPE MARTINO DI GIUDA ${ }^{1}$, PAOLO ETTORE GIANA ${ }^{1}$, VALENTINA VILLA ${ }^{2}$, and \\ SARA VALAGUZZA ${ }^{3}$ \\ ${ }^{I}$ Dept of ABC, Politecnico di Milano, Milan, Italy \\ ${ }^{2}$ Dept of DISEG, Politecnico di Torino, Torino, Italy \\ ${ }^{3}$ Dept of Italian and Supranational Public Law, Università degli Studi di Milano, Milan, Italy
}

\begin{abstract}
The research proposes an overview of the importation of a Relational Project Delivery Agreement (RPDA) in Italian legislation and the related issues. The AEC sector fragmentation, caused by an increase of building complexity and a change in the industry structure, is demanding a collaborative approach to the project to allow the possibility of a holistic vision based on a BIM approach. This work provides an overview of RPDAs applications on different contexts, highlighting benefits and issues related, including litigation resolution processes. A special focus has been kept in an Italian context, where the stagnant construction market needs to be revolutionized, and better interactions among stakeholders are required. The research imports and adapts an alliance agreement, FAC-1 (Framework Alliance Contract), on Italian framework, tailoring the most important features of the model to the Italian legislation. The goal of this work is providing a methodology to validate a standard form of contract, aiming at an added value to construction sector. Further developments consist in guidelines for contract management and evaluation of the project behavior during different phases of the process.
\end{abstract}

Keywords: Collaboration, Multiparty, Relational contracts, Framework alliance.

\section{INTRODUCTION}

This research proposes an analysis of the fragmentation of the construction sector, due to the contractual tradition, that obliges the different actors to act in pursuit of their own interests, producing a decrease in re-work and in lack of process optimizations performances, as well as collaboration with the supply chain (Akyuz et al. 2014). In most countries, construction projects are carried out by means of standard contracts, this procedure is new on the Italian scene, still used to building custom contracts (McKinsey Global Institute 2017). In order to optimize the entire process, an analysis on the worldwide different types of contracts and their implications for the construction process was carried out. In this sense, the study of the state of the art of collaborative contracts, Relational Project Delivery Agreements (RPDAs), has highlighted their wider potential impact on the sector. In order to import and adapt a collaborative procurement model in Italian legislation, collaboration has developed among some Italian universities (University of Milan, Milan Polytechnic and University of Brescia) and Prof. David Mosey at 
Kings College London. This alliance framework, considering the actual Italian procurement law, defines a new standard contract able to create collaborative interactions.

\section{RELATIONAL PROJECT DELIVERY AGREEMENTS}

Beside different contract approaches, there are different collaboration levels that could be set in a project (Lahdenperä 2012). The contract could be seen just as a promissory agreement among people recognized by the law, which sets the rules of interactions among the participants. According to Construction Leadership Council (CLC) (Construction Industry Council 2013) report on productivity, collaboration set in contractual stage, provides the basis for the Lean principles of reducing reworking and optimizing processes. The un-alignment of design team's goals and the site design work-flow goals create a waste, especially during the construction phase, resulting in time and budget overrun (Sacks et al. 2010). The lack of communication among team members produces (Tauriainen et al. 2016) misunderstanding resulting in an un-optimized building. All these circumstances are emphasized when collaboration doesn't involve all the participant to the project (Myerson 1999). In US, a new form of collaborative contracts is called Integrated Project Delivery (IPD) (AIACC 2014), it started as an alternative to the tradition Design-Bid-Built, in order to reduce complex project risks, and it imposed a mental shift in the fulfilling of the contract. In Europe Collaborative contracts are represented by Integrated Design, which does not involve linked contract to the framework. In this scenario, UK is the leading country that has applied and developed a RPDA for AEC industry. FAC-1, Framework Alliance Contract, is the first European contractual standard that is able to link more single set from a bilateral contract in a multi-party agreement. This approach is applicable in different scenarios and its methodology fits with BIM methodology and with collaborative system (Di Giuda et al. 2017a, Di Giuda et al. 2017b).

The European Directive 2014/24 recognizes the joint planning as one of the methods for building public works, the core principle of that partnership is that the design quality would be superior if the project is developed jointly. The Laws realized on January 28, 2016, Legislative Decree 50/2016, no. 11, (Italian Parliament 2016) has drastically limited the use of integrated tender based on technical design to "works or components characterized by a remarkable innovative or technological content". The reviewed Contracts Legislation has further restricted the joint design operation scope and execution contract to activities characterized by high technology or innovation elements that need the division of these phases. The value of a joint project development is superior when the project is produced by collaboration instead of a sequential development, so a joint alliance adoption impacts on time and costs.

\section{METHODOLOGY}

Productivity increase and time waste decrease are the RPDAs relevant advantages. The evolution of BIM methodology is imposing also a shift from traditional contract, which segregates different stakeholders, to a collaborative one. In this context, the BIM use helps in controlling and implementing the result of contractual evolution form during the whole project evolution. This research provides an analysis of the importation of a collaborative agreement in Italian legislation enhancing a BIM approach. A multidisciplinary group of researchers understood the possibility to import FAC-1 into Italian legislation. The FAC-1 was conceived and drafted by Prof. David Mosey $\mathrm{PhD}$, Director of the Centre for Construction Law and Dispute Resolution of King's College in London and was subsequently translated and adapted to the Italian legal context by the University of Milan. To prove the importation legitimacy, four levels of control analyses were put in practice: 
(i) First control: contractual model internal quality control in term of immediate comprehensibility of the terminologies used in the translation and the consistency of the contractual model with the reference market (Italian end European).

(ii) Second control: a semi-internal quality control developed in collaboration with Prof. David Mosey and based on a contract flux comparison between the two versions, explaining the modification of the contract to fit the Italian legislation.

(iii) Third control: external control that requires the help of some institutional entities, local authorities, universities, trade associations, representatives of the administrative judiciary and private operators. They provided some doubts and uncertainties, from different perspectives, which were analyzed and solved discrepancies.

(iv) Fourth control: second round of external control which took place during a round table discussion, where all the people, invited to discuss during the previous step to submit comments to the contract standard, attended the discussion. During this event, a few points of the standard were discussed, explained and commented for the regulatory bodies sensitivity, the coherence with Italian legislation and the market.

(v) The contributions received - further verified, also from the point of view of consistency with the original philosophy of the contractual model - were included in the final version of the document, which is therefore enriched by the experience of various leading players of the national panorama.

\section{ADAPTATION OF FAC-1 ON ITALIAN LEGISLATION}

The adaptation process of FAC-1 was developed by collaboration among people with different background and adapted the standard to Italian legislation, modifying its content in a drastic way in order to fit a different legislative standard. This research will provide a project and program management tool to clients, who would like to manage complex situations. According to the analysis conducted by OICE (Association of Organizations of Engineering and TechnicalEconomic Consulting), BIM projects are drastically increasing their importance in Italian market and for this reason, the framework will provide to it a solid base on which BIM methodology can fit the client requests. The Italian FAC-1 establishes a system regulates legal relations among several subjects involved in the implementation of one or more projects, defined as Programs, by linking several contracts with a view to encouraging collaboration and coordination of the various activities. Through the stipulation of FAC-1, parties undertake to work in a collaborative spirit and to carry out activities, called "Alliance Activities" - added value, site organization efficiency, BIM use - consistent with the aims identified by the Customer, which may be public or private.

\subsection{FAC-1: Structure and Features}

FAC-1 is structured as a Common Law Contract; and for this reason, it's useful starting from the General Conditions, containing the general rules, then moving on to the initial part.

The entire document is related to the Definitions, which states the way to read correctly the standard contracts. Consequently, the General Conditions, referred in the Cooperation Agreement, are the contract column. One of the main features of the contract is that it could be bended to the requests of the collaboration members just selecting the clauses that they want to apply. FAC-1 has pre-structured Annexes and Modules in order to set the requests made or the action carried by the collaboration. Through an information preset included in each request, each party structures the request in order to provide all the needed information. 


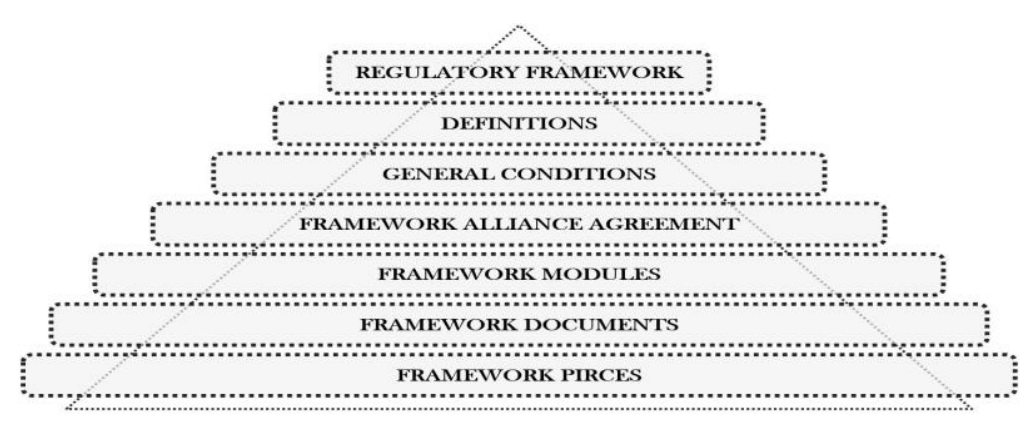

Figure 1. Hierarchical relationship among FAC-1 documents.

The provisions contained in the General Conditions and Annexes may be departed from or modified in the FAC-1, which is composed of several Modules, specifying respectively:

- The Objectives (KPI), Success measures, Targets, Objectives and Bonuses (Schedule 1);

- The Timetable (Schedule 2);

- The Risk Register (Schedule 3);

- Awarding Procedures (Schedule 4);

- Contractual Models (Schedule 5);

- Legal requirements and special terms (Schedule 6);

FAC-1 is a contract that suits a general goal called Objectives, which will be accomplished by specific Objectives measured through Key Performance Indicator (KPI) (Jonsson et al. 2017). The contract can pursue both the aims of a Project or a Program. The collaboration is set among the Client, the Alliance Manager and the Collaboration Members who sign the FAC-1.

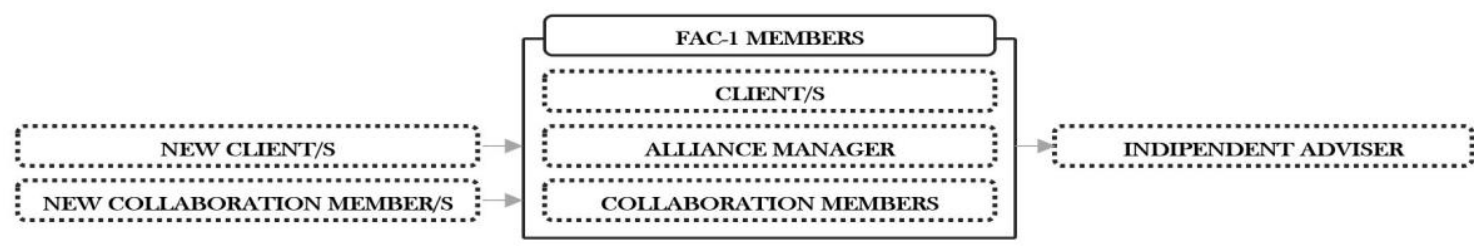

Figure 2. Structure of FAC-1.

The standard flexibility allows including more members to the collaboration both as a New Client and as a New Collaboration Member. To pursuit the Collaboration scope, a series of activities have to be completed and each member can propose a series of activities to the Client in order to optimize the project, their payment is at the discretion of the Alliance Manager and the Client. Sometimes the added value that is gathered from a new activity repay the effort extended in the action. Whether FAC-1 intervenes in a Program already in the design or execution phase, or where FAC-1 precedes the start of any activity related to a Program, the Collaboration Members are required to present their Collaboration Proposals, which may be limited to simple participation in meetings, drafting reports or sharing relevant information with other Collaboration Members, or they may consist in the provision of specific services. The Collaboration Activities execution takes place - according to the schedule in part two - on the basis of Requests formulated by the Client, indicating the contents to be implemented, the execution terms and the amount due for them, calculated on the basis of the Collaboration Price. Payment for Collaboration Activities shall be made in accordance with the conditions set out in 
FAC-1, a specific payment policy states the workflow of the procedure to trace all the payment among all the parties and to set the fee for delays. The Alliance Manager in relation to the Purposes of Collaboration monitors the performances and the Objectives, based on Members' activities, are assessed by shared KPI. The profit sharing is one of the keys of contracts based on collaborative procurements. For instance, the partaking of the supply chain can optimize the process and produce a huge reduction of the costs, thanks to shared procedures.

\subsection{Theoretical Examples of the Application of FAC-1}

In order to demonstrate FAC-1 flexibility, two examples of its application are presented, both on side of public and private investors. If we deal with the public sector, multiple municipalities can decide to optimize the street lighting service by creating a single management system for them all. Through this alliance, parties can be joined in the contractual scheme by establishing a dialogue aimed at a single goal dictated by the Client. Thanks to a shared supply chain, single installation companies can participate by offering, for example, an implementation of their System's performance. At the same time, the various companies being companies in the sector can help the maintenance manager to choose ways that are more appropriate by improving the Final Service. Finally, customers can choose which of the improvement proposals to adopt.

While if we deal in the context of the private client, the general contractor of a work decides to establish a collaboration agreement with other participants in order to optimize the process in terms of work quality, integration between design and construction and safety. In this scenario the designer could offer, as an additional service, the implementation through BIM methodology so as to reduce the design inefficiencies and the process inconsistency, in this sense the Client could accept an extra cost in the face of fewer problems in the execution phase and final saving greater than the cost incurred. In this way, proposals made by the other collaboration members can enhance the process offering costs management reduction through energy improvements or flows optimization through schedule changes. These collaborations improve the final result, setting an exchange of information and reducing misunderstandings and costs.

\section{DISCUSSION AND FURTHER DEVELOPMENT}

FAC-1 is a flexible contractual model in which parties are given the opportunity to consider efficiencies in the supply chain that make the flow of information more transparent and reduce the overall cost of performance. The Client could use the standard in order to create a collaboration, legally valid, among their sub-consultants or sub-contractors. The higher level of transparency and increased responsibility, towards both the Client and other Collaboration Components, required by each private operator in the pursuit of collaboration, are counterbalanced by the economic compensation provided. FAC-1 is a contract that regulates and manages the interrelations among different contracts and, namely, the relation among parties, which are not directly associated over a contract. Due to the Italian legislation, FAC-1 permits to connect different parties and to enhance collaboration among them, below some advantages achievable are shown:

- Different subjects' activities coordination with greater guarantees of results and with a reduction of unexpected interference, possible over-budget and overrun of time;

- Complex project efficient management with multiple subjects' contributions;

- Added value thanks to collaboration, in terms of work or service sustainability, site organization and working conditions efficiency, collaboration with the supply chain;

- All professionals' involvement in the collaboration in order to prevent or reduce the mistakes, which must be reported to Alliance Manager that improves project final quality; 
- Promoting transparency in relation to the specific aims and objectives of collaboration;

- Risks prevention and management during execution;

- Litigation reduction by preventing and extra-judicially handling possible claims.

In addition, FAC-1 is intended to build a solid legal framework for the BIM use in the construction sector, through the following means of developing a positive interaction among different design teams and linking the various phases of construction of a work (Alwash et al. 2017). FAC-1 approach invites the participants to submit their Collaboration Proposals and enhances the professional expertise, thereby exploiting economies of scale and achieving cash or other benefits.

At this point, the research provides a new approach to the problem of the inefficiency of the sector, in fact the collaboration that RPDA established among stakeholders is difficult to achieve and, most of the time, it is unattainable in a traditional process, although the promised success (Ghassemi et al. 2011). The research aims at providing to Italian and European legislation a contractual model, which aligns AEC sector performances to other sectors that already use this type of agreement. The new contract improves the processes management decreasing the public administration burden often due to litigations caused by traditional contractual procedures (Valaguzza 2018). The research will produce to integrate collaboration in work procedures, guideline for the contract application both for private and public users. The "Adda Martesana" Municipality will use this contractual model as part of the project to build a middle school in Liscate (Italy).

\section{References}

AIACC, Integrated Project Delivery: An Updated Working Definition, 2014.

Akyuz, G. A., Gursoy, G., and Celebi, N., Supply Chain Collaboration: A Conceptual Maturity Model, Industrial Engineering, 2333-2335, 2014.

Alwash, A., Love, P. E. D., and Olatunji, O., Impact and Remedy of Legal Uncertainties in Building Information Modeling, Journal of Legal Affairs and Dispute Resolution in Engineering and Construction, 1-7, 2017.

Construction Industry Council, Building Information Cic / BIM Protocol. Cic, 1-15, 2013.

Di Giuda, G. M., Villa, V., and Giana, P. E., Collaborative Contract with Building Information Modelling: Comparison Between USA and European Approach. ISEC-9, Resilient Structures and Sustainable Construction, Valencia, Spain, 2017a.

Di Giuda, G. M., Villa, V., Giana, P. E., Tagliabue, L. C., and Ciribini, A. L. C., LEAN Construction Applied to a BIM Process: How to Control Point Attribution in Meat Tender Process, Tema, 3(1), 3544, $2017 \mathrm{~b}$.

Ghassemi, R., and Becerik-Gerber, B., Transitioning to Integrated Project Delivery: Potential Barriers and Lessons Learned, Lean Construction Journal, 32-52, 2011.

Italian Parliament. D.Lgs. 50/2016 "Codice dei contratti Pubblici” e s.m.i., 2016.

Jonsson, H., and Rudberg, M., KPIs for Measuring Performance of Production Systems for Residential Buildings, Construction Innovation, 17(3), 381-403, 2017.

Lahdenperä, P., Making Sense of The Multi-Party Contractual Arrangements of Project Partnering, Project Alliancing and Integrated Project Delivery, Construction Management and Economics, 30(1), 57-79, 2012.

McKinsey Global Institute, Reinventing Construction: A Route to Higher Productivity, 1-155, 2017.

Myerson, R., B., Nash Equilibrium and the History of Economic Theory, Journal Economy Literature, 36, 1067-1082, 1999.

Sacks, R., Radosavljevic, M., and Barak, R., Requirements for Building Information Modeling Based Lean Production Management Systems for Construction, Automation in Construction, 2010.

Tauriainen, M., Marttinen, P., Dave, B., and Koskela, L., The Effects of BIM and Lean Construction on Design Management Practices, Procedia Engineering, 2016.

Valaguzza, S., Governare per contratto. CCLM Editoriale Scientifica, Napoli. 2018 